\title{
Ksantin Oksidaz İnhibitörü Yeni 1,2,3-Triazol Türevlerinin Sentezi, Karakterizasyonu ve Moleküler Doking Çalışmaları
}

\author{
Ayşe TAN ${ }^{*}$ \\ Muş Alparslan Üniversitesi, Teknik Bilimler Meslek Yüksekokulu, Gıda İşleme Bölümü, Muş \\ (ORCID: 0000-0003-2692-7923)
}

\begin{abstract}
$\ddot{O ̈ z}$
Bu çalışmada, yeni 1,2,3-triazol bileşiklerinin (4 ve 5) sentezi, karakterizasyonu, ksantin oksidaz enzimi üzerine in vitro inhibisyon etkilerinin incelenmesi ve moleküler doking çalışmaları gerçekleştirildi. Bu amaçla öncelikle; hedef ürünler (4 ve 5), bütadien sülfondan çıkılarak çeşitli kimyasal transformasyonlarla sentezlendi. Sentezlenen bütün bileşiklerin yapıları spektroskopik yöntemlerle aydınlatıldı. İkinci aşamada; $\mathbf{4}$ ve $\mathbf{5}$ bileşiklerinin ksantin oksidaz enzimi üzerine in vitro inhibisyon etkileri incelendi. Enzim inhibisyon sonuçlarına göre $\mathbf{4}\left(\mathrm{IC}_{50}=0.609\right.$ $\mu \mathrm{M})$ ve $\mathbf{5}\left(\mathrm{IC}_{50}=0.901 \mu \mathrm{M}\right)$ bileşiklerinin, ksantin oksidaz enzim inhibisyonu için ilaç olarak kullanılan allopurinolden $\left(\mathrm{IC}_{50}=1.143 \mu \mathrm{M}\right)$ daha güçlü inhibisyon etki gösterdiği tespit edildi. Son olarak; 4 ve $\mathbf{5}$ bileşiklerinin, ksantin oksidaz eziminin (PDB ID:3NVY) aktif kısmına bağlanma modları, moleküler doking çalışmaları ile açıklandı.
\end{abstract}

Anahtar kelimeler: 1,2,3-triazol, Ksantin oksidaz, 1,3-dipolar siklokatılma, Moleküler doking.

\section{The Synthesis, Characterization and Molecular Docking Studies of Novel 1,2,3-Triazole Derivatives as Xanthine Oxidase Inhibitor}

\begin{abstract}
In this study, the synthesis, characterization of novel 1,2,3-triazole compounds (4 and 5), investigation of their in vitro inhibition effects on xanthine oxidase and molecular docking studies were carried out. For this purpose, firstly; the target products ( $\mathbf{4}$ and $\mathbf{5}$ ) were synthesized by various chemical transformations starting from butadiene sulfone. All of the synthesized compounds were characterized by spectroscopic methods. In the second step; in vitro inhibition effects of compounds $\mathbf{4}$ and $\mathbf{5}$ on xanthine oxidase were investigated. According to the enzyme inhibition results, It was determined that compounds $4\left(\mathrm{IC}_{50}=0.609 \mu \mathrm{M}\right)$ and $\mathbf{5}\left(\mathrm{IC}_{50}=0.901 \mu \mathrm{M}\right)$ showed stronger inhibition effect than allopurinol $\left(\mathrm{IC}_{50}=1.143 \mu \mathrm{M}\right)$, which is used as a drug for inhibition of xanthine oxidase. Finally, the binding modes of compounds $\mathbf{4}$ and $\mathbf{5}$ in the active part of xanthine oxidase (PDB ID:3NVY) were explained by molecular docking studies.
\end{abstract}

Keywords: 1,2,3-triazole, Xanthine oxidase, 1,3-dipolar cycloaddition, Molecular docking.

\section{Giriş}

Orta çağda aşırı beslenme ve alkol alımı ile ilişkilendirilen ve halk arasında "kralların hastalığı" olarak adlandırılan gut hastalığı, eklemlerdeki ürik asitin kristalleşmesinden kaynaklanan bir tür enflamatuarromatizmal hastalıktır [1]. Kristalleşen ürik asit eklemlerde, tendonlarda ve çevre dokularda birikir. Kristallerin eklemlerin içinde ve çevresinde birikmesi, geri dönüşü olmayan eklem hasarına yol açar, bu hasarın sebebi, serum ürat konsantrasyonunun artmasıdır [1]. Hipoksantinin ksantine, ksantinin ürik asite dönüşümünü, ksantin oksidaz (XO) enzimi gerçekleştirir [2, 3]. XO enzimi, gut hastalığında önemli bir rolü olan ürik asitin oluşumuna, dolayısıyla gut hastalığına sebep olmaktadır. Bu nedenle gut hastalığının tedavisinde XO enzim inhibisyonu hayati önem taşımaktadır.

*Sorumlu yazar: a.tan@alparslan.edu.tr

Geliş Tarihi: 08.11.2019, Kabul Tarihi: 20.03.2020 
Yapısında pürin ihtiva eden allopurinol, uzun yıllardır kullanılan gut ilacıdır. Kronik gut hastalığında, kanda yüksek seviyede bulunan ürik asiti azaltmak için kullanılır [4]. Ağızdan alınan allopurinol, XO enzimini inhibe ederek, pürin metabolitlerinin ürik asite dönüşmesini engeller. Bir araştırmaya göre, allopurinol gibi pürin anoloğu ilaçların, anti metabolit aktivite sonucu nükleotitlere dönüştüğü rapor edilmiştir [5]. Ayrıca bu ilacın çok çeşitli ve ciddi yan etkilerinin olması kullanımını kısıtlamaktadır. $\mathrm{Bu}$ nedenle, güçlü XO inhibe edici aktiviteye sahip ve pürin içermeyen alternatif ilaçların keşfine ihtiyaç vardır [6-9].

1,2,3-triazol ve sübstitüe türevleri çok çeşitli biyolojik aktivitelerinden dolayı organik kimya, tıp kimyası özellikle ilaç keşfinde büyük bir öneme sahiptir [10]. 1,2,3-triazol yapısı içeren organik veya inorganik bir çok molekülün, antialerjik [11], antimikrobiyal [12], antibakteriyel [10], antitüberküler [10], $\alpha$-glukozidaz inhibitörü [13], SGLT2 inhibitörü [14], IDO inhibitörü [15], asidik korozyon inhibitörü [16] gibi çok sayıda potansiyel biyolojik aktivite gösterdikleri birçok kaynakta bildirilmiştir. Bazı farmasotik aktif 1,2,3-triazol bileşiklerine Şekil 1 de örnek verilmiştir.

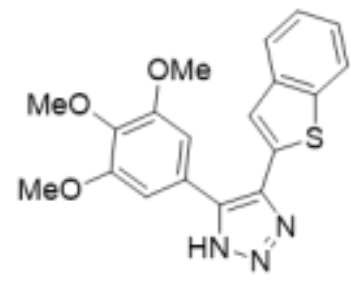

Antikanser

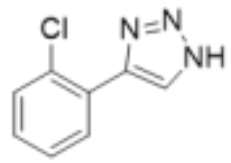

IDO inhibitörũ

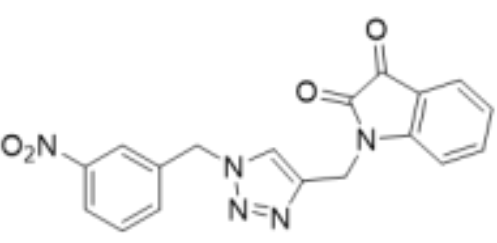

Antitüberküler

Şekil 1. Farmasotik aktif bazı 1,2,3-triazol bileşikleri

Yapılan bu çalışma kapsamında, 1,2,3-tirazol yapısını içeren organik moleküllerin güçlü biyolojik özellik göstermeleri ve XO enzim inhibisyonu için duyulan etkili ilaç gereksiniminden yola çıkılarak, 1lıman reaksiyon şartlarında, literatürde henüz bilinmeyen yeni 1,2,3-triazol bileşiklerinin (4 ve 5) sentezi, karakterizasyonu ve bu bileşiklerin XO inhibisyon etkisi incelendi. Ayrıca moleküler doking çalışması yapılarak 3D enzim-molekül etkileşimleri belirlendi.

\section{Materyal ve Metot}

\subsection{4 ve 5 bileşiklerinin sentezi}

1,2,3-triazol türevi olan 4 ve 5 bileşiklerinin sentezi için, öncelikle sentezi literatürde bilinen $\mathbf{1}$ [17] bileşiği, bütadien sülfon ile dimetil asetilen dikarboksilatın ksilen ortamında, $145^{\circ} \mathrm{C}$ 'de 2 saat süren [4+2] siklokatılma reaksiyonu ile sentezlendi [17] (Şekil 2). 1 bileşiğinin $m$-CPBA[18] ile $\mathrm{CH}_{2} \mathrm{Cl}_{2}$ ortamında $0^{\circ} \mathrm{C}$ 'de 6 saat süren epoksidasyon reaksiyonu ile tek ürün olarak literatürde bilinen 2 [19,20] bileşiği elde edildi (Şekil 2). Bir sonraki kademede, 2 bileşiğinin $\mathrm{NaN}_{3}$ [21] ile $\mathrm{NH}_{4} \mathrm{Cl}$ varlığında, $\mathrm{MeOH}$ içerisinde $70^{\circ} \mathrm{C}$ 'de epoksit açılma reaksiyonu gerçekleştirildi (Şekil 2). Bu reaksiyon ile 1,2,3-triazol sentezi için kilit rol oynayan, literatürde henüz bilinmeyen, hidroksi-azido yapısında yeni $\mathbf{3}$ bileşiği sentezlendi.

3 bileşiğinin daha sonra sırasıyla fenil asetilen ve 1-pentin ile $\mathrm{Cu}(\mathrm{I})$ katalizörlüğünde 1,3-dipolar siklokatılma reaksiyonu [22,23] gerçekleştirilerek literatürde olmayan, yeni 1,2,3-triazol türevi 4 ve 5 bileşikleri sentezlendi (Şekil 2). 


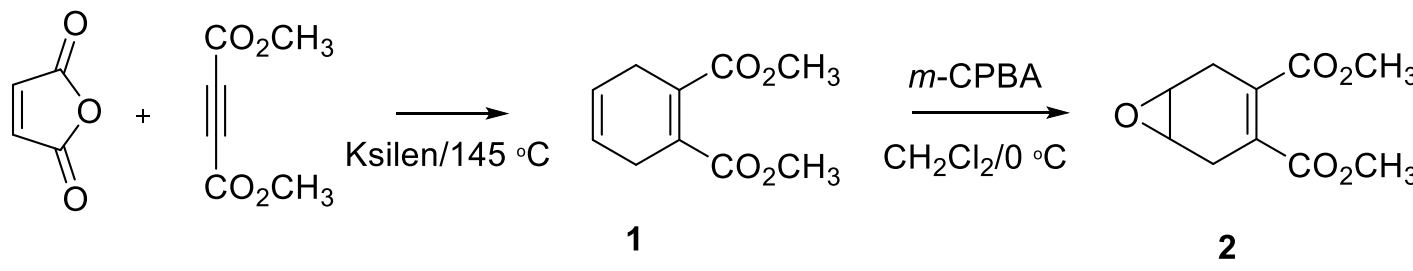<smiles>[R]c1cn(C2CC(C(=O)OC)=C(C(=O)OC)CC2O)nn1</smiles>

4. $\mathrm{R}:-\mathrm{Ph}$

5. $\mathrm{R}:-\mathrm{CH}_{2} \mathrm{CH}_{2} \mathrm{CH}_{3}$

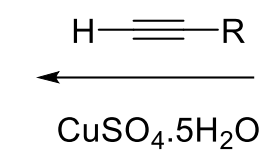

Sodyum $L$-askorbat

$\mathrm{MeOH} / 25^{\circ} \mathrm{C}$<smiles>CO[NbH2]OC(=O)NCO</smiles><smiles></smiles>

3

Şekil 2. Triazol türevlerinin (4 ve 5) sentez basamakları

\subsection{Spektral Analiz}

2 bileşiğine ait ${ }^{1} \mathrm{H}$ NMR spektrumu incelendiğinde; $\delta=3.8(6 \mathrm{H})$ ppm'deki kimyasal kayma değeri $\mathrm{OCH}_{3}$ protonlarını, $\delta=3.4(2 \mathrm{H})$ ppm'deki singlet sinyal epoksit grubunun bağlı olduğu -O-C-H* protonlarının varlığını, $\delta=2.9(2 \mathrm{H})$ ppm ve $2.7(2 \mathrm{H})$ ppm'deki kimyasal kayma değerleri ise siklohekzen halkasındaki $\mathrm{CH}_{2}$ protonlarını göstermektedir (Şekil 3). Hidroksi-azido yapısındaki 3 bileşiğine ait IR spektrumunda; $v=3453.57 \mathrm{~cm}^{-1}$ de gözlemlenen gerilme titreşimleri OH grubuna, $v=2103.57 \mathrm{~cm}^{-1}$, de gözlemlenen gerilme titreşimleri ise karakteristik azido $\left(-\mathrm{N}_{3}\right) \mathrm{N}-\mathrm{N}$ gerilme titreşimlerine aittir (Şekil 4). 3 bileşiğine ait ${ }^{1} \mathrm{H}$ NMR spektrumu incelendiğinde, 2 bileşiğinin $\delta=3.4 \mathrm{ppm}$ deki epoksitin $-\mathrm{O}-\mathrm{C}-\mathrm{H}^{*}$ protonlarına ait sinyalin, $\delta=3.8 \mathrm{ppm}(1 \mathrm{H})$ ve $3.6 \mathrm{ppm}$ 'de $(1 \mathrm{H})$ iki multiplet sinyale yarılması epoksit halkasının azit grubu ile açıldığının bir diğer göstergesidir, $\delta=2.8(2 \mathrm{H})$ ppm ve $2.4(2 \mathrm{H})$ ppm'deki kimyasal kayma değerleri de siklohekzen halkasındaki $\mathrm{CH}_{2}$ protonlarına aittir (Şekil 3).

Azit-alkin 1,3-dipolar siklokatılma reaksiyonunun gerçekleştiği 1,2,3-triazol halkasındaki N$\mathrm{C}=\mathrm{C}-\mathrm{H}$ protonuna ait singlet sinyal ile kolaylıkla belirlenebilmektedir. $\mathrm{Bu}$ sinyaller, 4 bileşiğinin ${ }^{1} \mathrm{H}$ NMR spektrumunda fenil grubunun aromatik sinyalleri ile çakışırken, 5 bileşiğinin ${ }^{1} \mathrm{H}$ NMR spektrumunda $\delta=7.3$ ppm'deki singlet sinyal net olarak görülmektedir. 1,2,3-triazol halkasındaki kuarterner karbon atomunun (N-C* $=\mathrm{C}-\mathrm{H})$ sinyalleri ${ }^{13} \mathrm{C}$ NMR spektrumunda 4 ve 5 bileşiği için sırasıyla $\delta=146.4$ ppm ve 147.2 ppm' de gözlemlenmiştir. 5 bileşiğinin ${ }^{1} \mathrm{H}$ NMR spektrumu incelendiğinde (Şekil 5); siklohekzen halkasındaki HO-C-H* ve N-C-H protonları sirasıyla $\delta=4.5(1 \mathrm{H})$ ppm ve $4.4(1 \mathrm{H})$ ppm'de ester grubuna ait $\mathrm{OCH}_{3}$ protonları $\delta=3.8(3 \mathrm{H}) \mathrm{ppm}, 3.7(3 \mathrm{H}) \mathrm{ppm}$ 'de sinyal verirken, triazol halkasına bağlı $\mathrm{CH}_{2}$ protonları ile siklohekzen halkasındaki $\mathrm{CH}_{2}$ protonları çakışık halde $\delta=3.1(3 \mathrm{H})$ ppm ve $2.5(3 \mathrm{H})$ ppm'de sinyal vermiştir.

5 bileşiğine ait $\mathrm{OH}$ grubu sinyalleri, IR spektrumunda $v=3275.00 \mathrm{~cm}^{-1}$, deki gerilme titreşimleri ile karakterize edildi. Yine triazol halkasına bağlı diğer alkil protonları sırasıyla $\delta=1.6\left(2 \mathrm{H}, \mathrm{CH}_{2}\right) \mathrm{ppm}, 0.9$ $\left(3 \mathrm{H}, \mathrm{CH}_{3}\right)$ ppm'deki sinyaller ile karakterize edildi. 4 bileşiğinin ${ }^{1} \mathrm{H}$ NMR spektrumunda fenil grubuna ait sinyaller $\delta=7.7-7.3(5 \mathrm{H}) \mathrm{ppm}$ arasında gözlemlenirken, diğer protonlar 5 bileşiğinin ${ }^{1} \mathrm{H}$ NMR spektrumu ile benzer sinyaller vermiștir.

5 bileşiğinin ${ }^{13} \mathrm{C}$ NMR spektrumu incelendiğinde (Şekil 5); $\delta=167.5$ ppm ve 166.8 ppm'deki sinyaller karbonil karbonuna $(\mathrm{C}=\mathrm{O}), \delta=134.5 \mathrm{ppm}$ ve 131.1 ppm'deki sinyaller siklohekzen halkasındaki çift bağ karbonlarına $(\mathrm{C}=\mathrm{C}), \delta=121.8$ ppm deki sinyal triazol halkasındaki $\mathrm{N}-\mathrm{C}-\mathrm{H}$ 
karbonuna, $\delta=67.5$ ppm'deki sinyal siklohekzen halkasindaki C-OH, ve $\delta=61.8$ ppm'de ve C-N-N karbonuna aitken, sirasıyla $\delta=34.5 \mathrm{ppm}$ ve 31.9 ppm'deki sinyaller siklohekzen halkasindaki $\mathrm{CH}_{2}$ karbonlarına, $\delta=52.56 \mathrm{ppm}$ ve $52.52 \mathrm{ppm}$ 'deki sinyaller ester grubundaki metil karbonlarına $\left(\mathrm{OCH}_{3}\right)$, $\delta=27.4\left(\mathrm{CH}_{2}\right)$ ppm, $22.4\left(\mathrm{CH}_{2}\right)$ ppm, $13.8\left(\mathrm{CH}_{3}\right)$ ppm'deki sinyaller triazol halkasına bağlı alkil zincirinin karbonlarına aittir. 4 bileşiğine ait ${ }^{13} \mathrm{C}$ NMR spektrumu incelendiğinde, aromatik sinyaller hariç diğer sinyaller 5 bileşiğinin ${ }^{13} \mathrm{C}$ NMR spektrumu ile benzerdir.

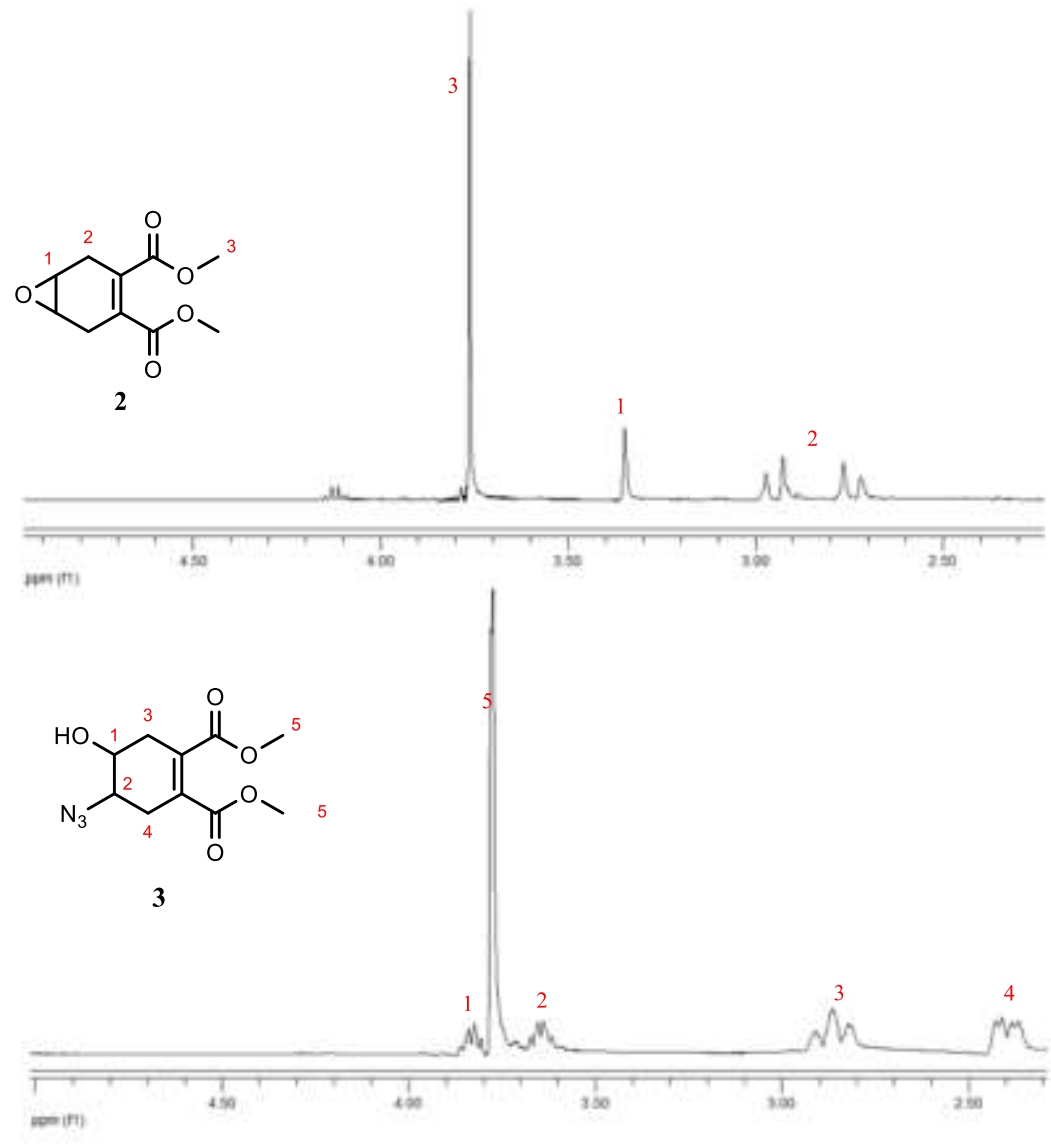

Şekil 3. 2 ve 3 bileşiklerinin ${ }^{1} \mathrm{H}$ NMR spektrumu (400 MHz)

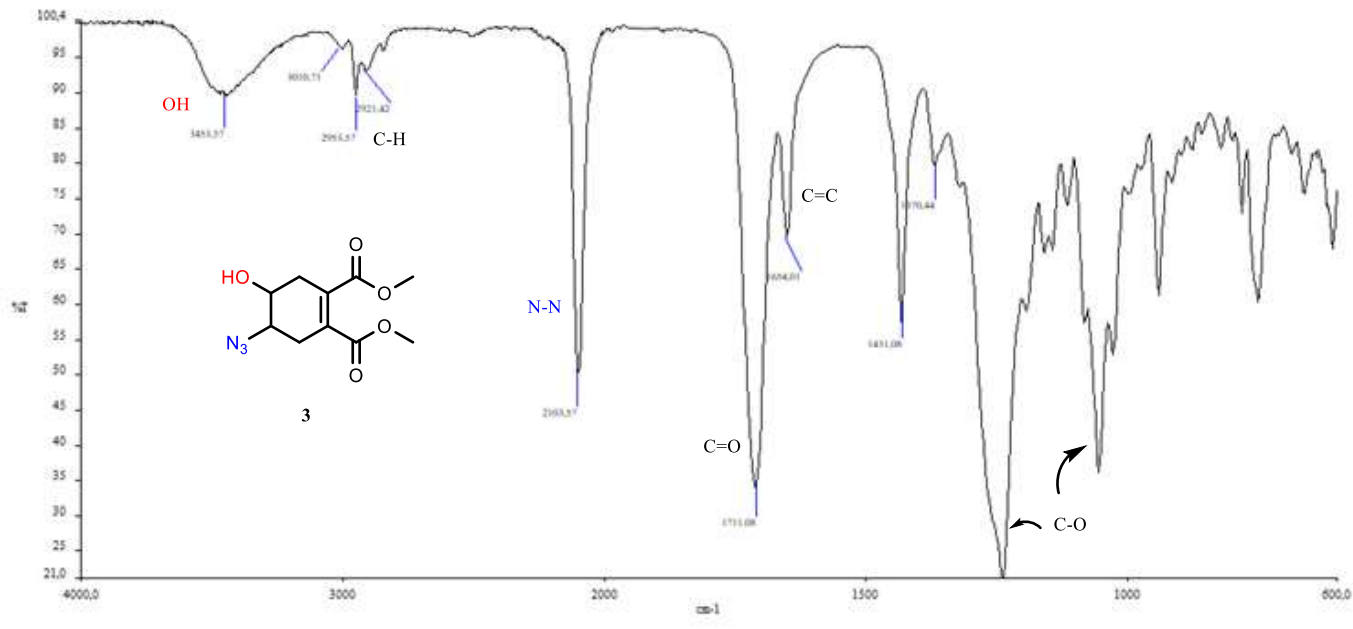

Şekil 4. 3 bileşiğinin IR spektrumu 

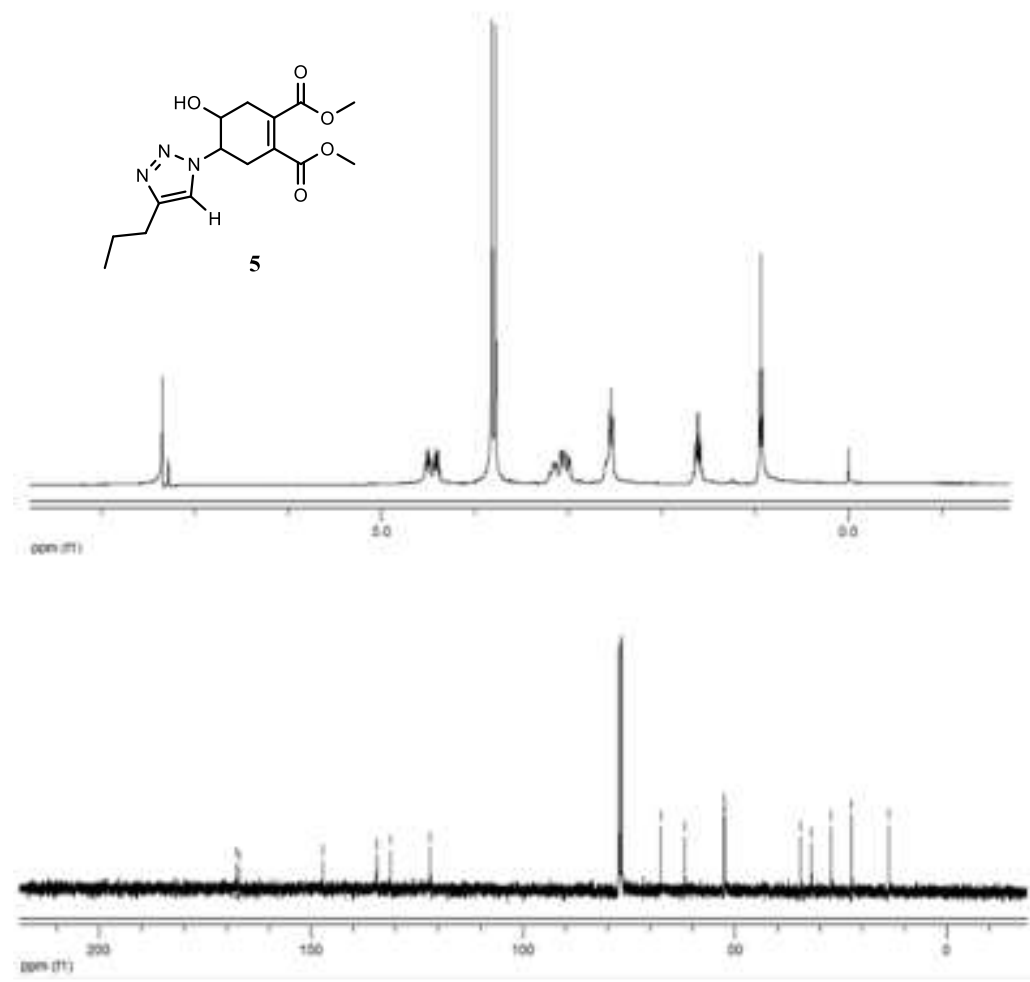

Şekil 5. 5 bileşiğine ait ${ }^{1} \mathrm{H}$ NMR (400 MHz) ve ${ }^{13} \mathrm{C}$ NMR spektrumu (100 MHz)

\subsection{4 ve 5 bileşiklerinin Ksantin Oksidaz (XO) Enzimi Üzerine İn Vitro İnhibisyon Etkilerinin İncelenmesi}

4 ve 5 bileșiklerinin Ksantin Oksidaz enzimi üzerine in vitro inhibisyon deneyi, XO inhibisyonu için ilaç olarak kullanılan allopurinol ile kıyaslanarak gerçekleştirildi. 4, 5 ve allopurinol için $\mathrm{IC}_{50}$ değerleri hesaplandı (Tablo 1). Sonuçlara göre inhibisyon aktiviteleri $\mathbf{4}>\mathbf{5}>$ allopurinol sırasında değişmektedir.

Tablo 1. Ksantin oksidaz enzim inhibisyonunun $\mathrm{IC}_{50}$ değerleri.

\begin{tabular}{ccc}
\hline Bileşik & $\mathbf{I C}_{\mathbf{5 0}}(\boldsymbol{\mu M})$ & $\mathbf{R}^{\mathbf{2}}$ \\
\hline $\mathbf{4}$ & $0.609 \pm 0.006$ & 0.987 \\
\hline $\mathbf{5}$ & $0.901 \pm 0.031$ & 0.976 \\
\hline Allopurinol & $1.143 \pm 0.019$ & 0.989 \\
\hline
\end{tabular}

\subsection{Moleküler Doking}

Allopurinol, 4 ve 5 bileşiklerinin deneysel enzim inhibisyon sonuçlarını teorik olarak desteklemek üzere moleküler doking çalışması gerçekleştirildi. Reseptör proteinin $\mathrm{C}$ zinciri ürerinde yapılan doking çalışmalarına göre; 4 ve 5 bileşiklerinin proteinin aktif kısmı ile H-bağı yapmadığı, hidrofobik etkileşim yaptığı görüldü (Tablo 2). Allopurinolün, 4 ve 5 bileşiklerinin aksine GLU232, THR440, VAL441 ile konvansiyonel H-bağı, PHE344, PHE439 ile yoğun pi-pi etkileşimi ve ALA509, ALA508, LEU303 ile pi-alkil etkileşimi, ARG310, SER306, LEU444, PRO506 ile van der Waals etkileşimi yaptığı görüldü (Şekil 8)[24]. 4 bileşiğinin, ARG880, THR1010, SER876, PHE649, GLU879, GLU802, LEU648, LYS771, PHE1013 ile van der Waals etkileşimi, HIS875 ile C-H bağ1, PHE914, PHE1009 ile yoğun pipi etkileşimi, ALA1079, VAL1011, LEU1014, LEU873 ile zayıf pi-pi etkileşimi yaptığı görüldü (Şekil 6). 5 bileşiğinin, HIS875 ile yoğun pi-pi etkileşimi, PHE649 ile pi-sigma etkileşimi, ARG871 ile alkil etkileşimi, PHE1013, LEU648, SER876, LEU873, VAL1011, LEU1014 ile van der Waals etkileşimleri yaptığı görüldü (Şekil 7). 


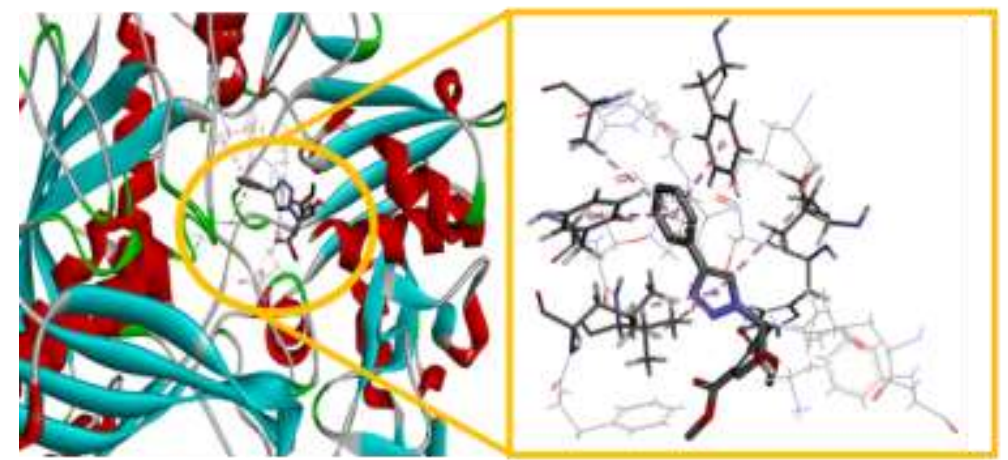

(a)

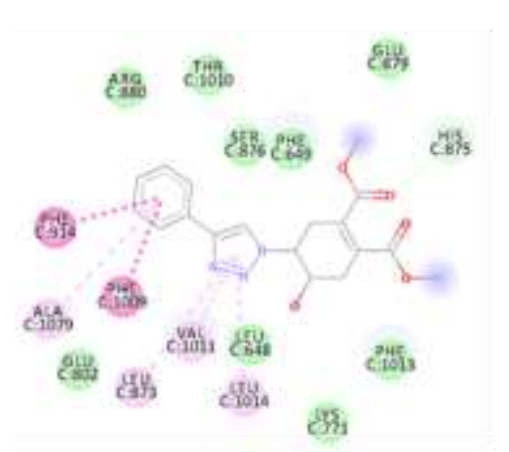

(b)

Şekil 6. 4 bileşiğinin Ksantin oksidaz (PDB ID:3NVY) ile a) bağlanma modu ve reseptör-ligand etkileşimi 3D gösterimi ( 4 bileşiği top-çubuk görünümde, proteinin etkileşim yaptığı kısımlar ise çizgi ve çubuk gösterimi ile belirtilmiştir), b) reseptör-ligand etkileşiminin 2D gösterimi

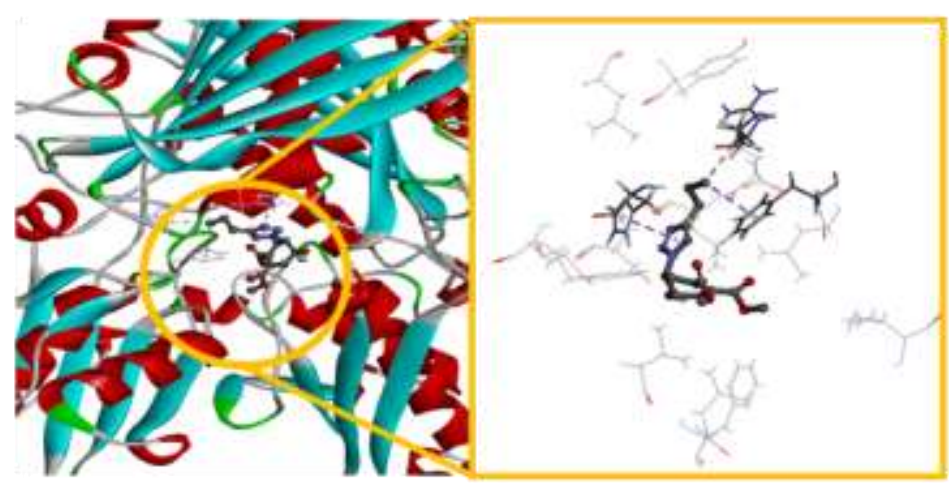

(a)

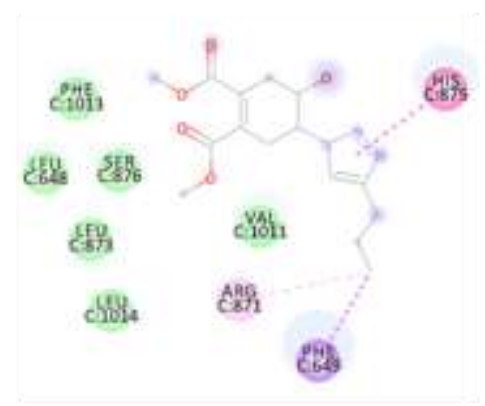

(b)

Şekil 7. 5 bileşiğinin Ksantin Oksidaz (PDB ID:3NVY) ile a) bağlanma modu ve reseptör-ligand etkileşimi 3D gösterimi ( 5 bileşiği top-çubuk görünümde, proteinin etkileşim yaptı̆̆ı kısımlar ise çizgi ve çubuk gösterimi ile belirtilmiştir), b) reseptör-ligand etkileşimi 2D gösterimi

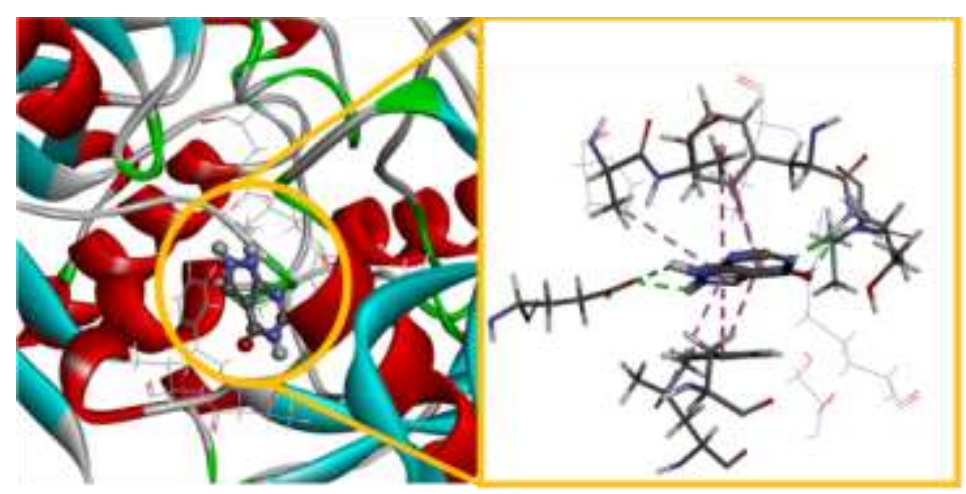

(a)

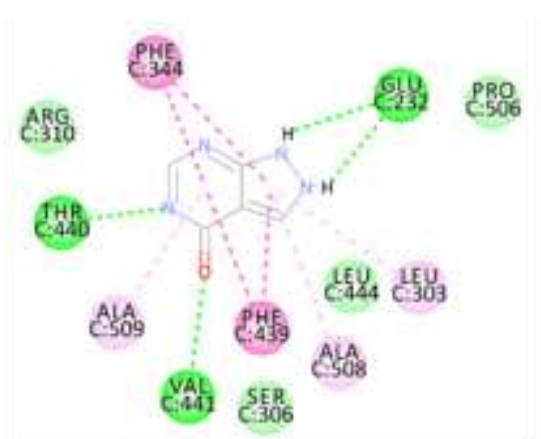

(b)

Şekil 8. Allopurinol bileşiğinin Ksantin Oksidaz (PDB ID:3NVY) ile a) bağlanma modu ve reseptör-ligand etkileşimi 3D gösterimi (Allopurinol bileşiği top-çubuk görünümde, proteinin etkileşim yaptığı kısımlar ise çizgi ve çubuk gösterimi ile belirtilmiştir), b) reseptör-ligand etkileşimi 2D gösterimi 
Tablo 2. 4, 5 ve allopurinol bileşiklerinin Ksantin Oksidaz enzimi aktif kısmı ile yaptığı hidrofobik etkileşim

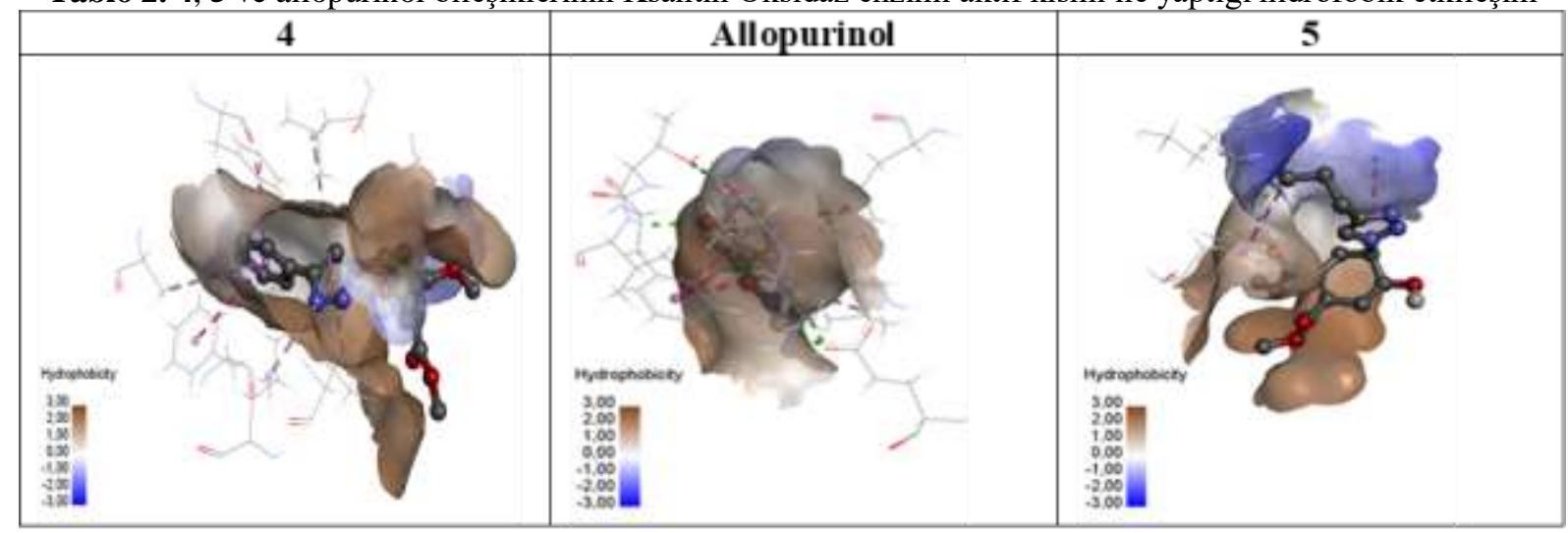

\section{Bulgular}

\subsection{Sentez}

Bütün reaktif ve soventler Sigma-Aldrich’ten satın alınmış ve saflaştırma işlemi uygulanmamıştır. ${ }^{1} \mathrm{H}$ NMR ve ${ }^{13} \mathrm{C}$ NMR spektrumları Bruker $400 \mathrm{MHz}$ spektrofotometresi ile alındı. IR spektrumları Perkin Elmer Spektrometresi ile ATR başlık kullanılarak alındı, 4000-600 $\mathrm{cm}^{-1}$ arası esas alındı. Erime noktası tayini için Thermo Scientific Melting Point cihazı kullanıldı. Kütle spektrumları Agilent Technologies 6530 Accurate-Mass Q-TOF LC/MS ile alındı.

\section{Dimetil siklohekza-1,4-dien-1,2-dikarboksilat (1)}

Bütadien sülfon $(0.5 \mathrm{~g}, 4.23 \mathrm{mmol}) 5 \mathrm{ml}$ ksilen içerisinde çözüldü ve karışıma dimetil asetilen di karboksilat (1.2 g, $8.46 \mathrm{mmol})$ ilave edilerek ortamın sıcaklığ $145^{\circ} \mathrm{C}$ 'ye getirildi. Reaksiyon ince tabaka kromatografisi (ITK) ile takip edildi, 2 saat sonra durduruldu. Çözücüsü düşük basınçta uzaklaştırıldı. Ham ürün kolon kromatografisi ile \% $5 \mathrm{EtOAc/n}$-Hekzan çözücü sisteminde saflaştırıldı. 1 bileşiği \% $50(0.41 \mathrm{~g}, 2.09 \mathrm{mmol})$ verimle viskoz, renksiz sivı olarak elde edildi [17].

\section{Dimetil 7-oksabisiklo[4.1.0]hept-3-en-3,4-dikarboksilat (2)}

1 bileşiği $0{ }^{\circ} \mathrm{C}$ 'de $(0.5 \mathrm{~g}, 2.54 \mathrm{mmol}) 10 \mathrm{~mL} \mathrm{CH}_{2} \mathrm{Cl}_{2}$ içerisinde çözüldü. Reaksiyon ortamına $m$-CPBA $(0.5 \mathrm{~g}, 3.05 \mathrm{mmol})$ ilave edildi. $0^{\circ} \mathrm{C}$ 'de başlayan reaksiyon, oda sıcaklığında devam ettirildi. Reaksiyon İTK ile takip edildi, 6 saat sonra durduruldu. Karışım, önce $\% 10$ 'luk $10 \mathrm{~mL} \mathrm{NaHCO} 3$ çözeltisi ile nötralize edildi, ardından $10 \mathrm{~mL} \mathrm{CH}_{2} \mathrm{Cl}_{2}$ ve $3 \times 10 \mathrm{~mL}$ su ilave edilerek ekstrakte edildi. Organik faz $\mathrm{Na}_{2} \mathrm{SO}_{4}$ üzerinden kurutulup, çözücüsü düşük basınçta uzaklaştırıldı. Ham ürün kolon kromatografisi ile $\% 15 \mathrm{EtOAc/n}$-Hekzan çözücü sisteminde saflaştırıldı. 2 bileşiği \%80 (0.42 g, $2 \mathrm{mmol})$ verimle viskoz, açık sarı, sıvı olarak elde edildi. ${ }^{1} \mathrm{H}$ NMR $\left(\delta, \mathrm{ppm}, 400 \mathrm{MHz}, \mathrm{CDCl}_{3}\right): 3.8\left(s, 6 \mathrm{H}, \mathrm{OCH}_{3}\right), 3.4(s, 2 \mathrm{H})$, $2.9(d, \mathrm{AB}$ sisteminin A kısm1, $J=17.6 \mathrm{~Hz}, 2 \mathrm{H}), 2.7(d, \mathrm{AB}$ sisteminin B k1sm1, $J=19.2 \mathrm{~Hz}, 2 \mathrm{H}),{ }^{13} \mathrm{C}$ $\operatorname{NMR}\left(\delta, p p m, 100 \mathrm{MHz}, \mathrm{CDCl}_{3}\right): 167.9,130.2,52.3,49.8,26.5$

\section{Dimetil 4-azido-5-hidroksisikloheks-1-en-1,2-dikarboksilat (3)}

2 bileșiği $(0.5 \mathrm{~g}, 2.35 \mathrm{mmol}) 20 \mathrm{~mL} \mathrm{MeOH}$ içerisinde çözüldü, karışıma $(0.45 \mathrm{~g}, 7.05 \mathrm{mmol}) \mathrm{NaN}_{3}$ ve $\mathrm{NH}_{4} \mathrm{Cl}(0.37 \mathrm{~g}, 7.05)$ ilave edildi. Reaksiyon sicakl $\breve{g}_{1} 70^{\circ} \mathrm{C}$ 'ye getirildi. Reaksiyon İTK ile takip edildi ve 24 saat sonra durduruldu. Çözücüsü düşük basınçta uzaklaştırıldı. Karışım, $20 \mathrm{~mL}$ EtOAc ve 3x10 $\mathrm{mL}$ su ilave edilerek ekstrakte edildi. Organik faz $\mathrm{Na}_{2} \mathrm{SO}_{4}$ üzerinden kurutulup, ham ürün kolon kromatografisi ile \%10 EtOAc/n-Hekzan çözücü sisteminde saflaştırıldı. 3 bileşiği \%80 (0.48 g, 1.88 mmol) verimle viskoz, açık sarı sıvı olarak elde edildi. ${ }^{1} \mathrm{H}$ NMR $\left(\delta, \mathrm{ppm}, 400 \mathrm{MHz}, \mathrm{CDCl}_{3}\right): 3.8(\mathrm{~m}$, $1 \mathrm{H}), 3.7\left(s, 6 \mathrm{H}, \mathrm{OCH}_{3}\right), 3.6(\mathrm{~m}, 1 \mathrm{H}), 2.8(t d, J=4,8 \mathrm{~Hz}, \mathrm{AB}$ sisteminin A kısmı, $2 \mathrm{H}), 2.4(d d d, J=4$, 8, $21.2 \mathrm{~Hz}, \mathrm{AB}$ sisteminin B k1sm1, 2H), ${ }^{13} \mathrm{C} \mathrm{NMR}\left(\delta, \mathrm{ppm}, 100 \mathrm{MHz}, \mathrm{CDCl}_{3}\right): 167.7,167.1,133.5$, 
131.2, 68.2, 60.9, 52.5, 33.2, 30.2, IR $\left(\mathrm{cm}^{-1}\right): 3453.57,3010.71,2953.57,2921.42,2103.57,1711.08$, 1654.01, 1431.08, 1370. 44, HR-ESI-MS: $256.09138[M+\mathrm{H}]^{+}$, hesaplanan:256.09335 $\left.[M+\mathrm{H}]^{+}\right)$

\section{Dimetil 4-hidroksi-5-(4-fenil-1H-1,2,3-triazol-1-il)siklohekz-1-en-1,2-dikarboksilat (4)}

3 bileşiği (0.44 g, $1.72 \mathrm{mmol}) 10 \mathrm{~mL} \mathrm{MeOH}$ içerisinde çözüldü. Oda sıcaklığında, karışıma sırasıyla, 5 mL suda çözülmüş sodyum $L$-askorbat $(0.034 \mathrm{~g}, 0.172 \mathrm{mmol})$ ve $5 \mathrm{~mL}$ suda çözülmüş $\mathrm{CuSO}_{4} .5 \mathrm{H}_{2} \mathrm{O}$ (0.042 g, $0.172 \mathrm{mmol})$ ilave edildi. Homojen karışıma fenil asetilen $(0.19 \mathrm{~mL}, 1.72 \mathrm{mmol})$ damla damla ilave edildi. Reaksiyon ITTK ile takip edildi ve 24 saat sonra durduruldu. Karışım, $10 \mathrm{~mL}$ EtOAc ilave edilerek ekstrakte edildi. Organik faz $\mathrm{Na}_{2} \mathrm{SO}_{4}$ üzerinden kurutuldu. Ham ürün kolon kromatografisi ile $\% 50 \mathrm{EtOAc/} n$-Hekzan çözücü sisteminde saflaștırıldı. 4 bileșiği $\% 90(0.55 \mathrm{~g}, 1.55 \mathrm{mmol})$ verimle, mat beyaz renkli, katı kristal olarak elde edildi. E.N: $159{ }^{\circ} \mathrm{C},{ }^{1} \mathrm{H}$ NMR $\left(\delta, \mathrm{ppm}, 400 \mathrm{MHz}, \mathrm{CDCl}_{3}\right): 7.7(s$, $1 \mathrm{H}), 7.5(\mathrm{~m}, 2 \mathrm{H}), 7.3(\mathrm{~m}, 3 \mathrm{H}), 4.5(\mathrm{~m}, 1 \mathrm{H}), 4.4 .(s, 1 \mathrm{H}), 3.8(s, 3 \mathrm{H}), 3.79(s, 3 \mathrm{H}), 3.29(\mathrm{~m}, 1 \mathrm{H}), 3.09(\mathrm{~m}$, $2 \mathrm{H}), 2.6(\mathrm{~m}, 1 \mathrm{H}),{ }^{13} \mathrm{C}$ NMR $\left(\delta, \mathrm{ppm}, 100 \mathrm{MHz}, \mathrm{CDCl}_{3}\right): 167.6,166.8,146.4,134.6,131.1,29.4,128.6$, 128.04, 125.1, 121.2, 67.8, 62.6, 52.5, 52.5, 34.6, 31.4, IR $\left(\mathrm{cm}^{-1}\right): 3432.14,3128.57,3014.28,2953.57$, 2903.57, 1720.00, 1657.57, 1486.36, 1461.40, 1427.51, HR-ESI-MS: $358.14222[M+\mathrm{H}]^{+}$, hesaplanan: $\left.358.14030[M+\mathrm{H}]^{+}\right)$

\section{Dimetil 4-hidroksi-5-(4-propil-1H-1,2,3-triazol-1-il)siklohekz-1-en-1,2-dikarboksilat (5)}

3 bileşiği $(0.44,1.72 \mathrm{mmol}) 10 \mathrm{~mL} \mathrm{MeOH}$ içerisinde çözüldü. Oda sıcaklığında, karışıma sırasıyla, 5 $\mathrm{mL}$ suda çözülmüş sodyum $L$-askorbat $(0.034 \mathrm{~g}, 0.172 \mathrm{mmol})$ ve $5 \mathrm{~mL}$ suda çözülmüş $\mathrm{CuSO}_{4} .5 \mathrm{H}_{2} \mathrm{O}$ $(0.042 \mathrm{~g}, 0.172 \mathrm{mmol})$ ilave edildi. Homojen karışıma 1-pentin $(0.17 \mathrm{~mL}, 1.72 \mathrm{mmol})$ damla damla ilave edildi. Reaksiyon oda sıcaklığında, ITTK ile takip edildi ve 24 saat sonra durduruldu. Karıșım, $10 \mathrm{~mL}$ EtOAc ilave edilerek ekstrakte edildi. Organik faz $\mathrm{Na}_{2} \mathrm{SO}_{4}$ üzerinden kurutuldu. Ham ürün kolon kromatografisi ile \% $50 \mathrm{EtOAc/n-Hekzan} \mathrm{çözücü} \mathrm{sisteminde} \mathrm{saflaştırıldı.} 5$ bileşiği \% $95(0.53 \mathrm{~g}, 1.63$ mmol) verimle, parlak sarı renkli, katı kristal olarak elde edildi. E.N: $118{ }^{\circ} \mathrm{C},{ }^{1} \mathrm{H}$ NMR $(\delta$, ppm, 400 $\left.\mathrm{MHz}, \mathrm{CDCl}_{3}\right): 7.3(s, 1 \mathrm{H}), 4.5(m, 1 \mathrm{H}), 4.4(m, 1 \mathrm{H}), 3.8(s, 3 \mathrm{H}), 3.7(s, 3 \mathrm{H}), 3.1(m, 3 \mathrm{H}), 2.5(m, 3 \mathrm{H})$, $1.6(p, J=7.6 \mathrm{~Hz}, 2 \mathrm{H}), 0.9(t, J=7.6 \mathrm{~Hz}, 3 \mathrm{H}),{ }^{13} \mathrm{C} \mathrm{NMR}\left(\delta, \mathrm{ppm}, 100 \mathrm{MHz}, \mathrm{CDCl}_{3}\right): 167.5,166.8$, 147.2, 134.5, 131.1, 121.8, 67.5, 61.8, 52.56, 52.52, 34.5, 31.9, 27.4, 22.4, 13.8, IR $\left(\mathrm{cm}^{-1}\right): 3275.00$, 2964.28, 2928.57, 2875.00, 1725.35, 1709.29, 1646.87, 1547.00, 1434.64, HR-ESI-MS: 324.15707 $[M+\mathrm{H}]^{+}$, hesaplanan: $\left.324.15595[M+\mathrm{H}]^{+}\right)$

\subsection{4 ve 5 bileşiklerinin Ksantin Oksidaz (XO) inhibisyon etkilerinin in vitro ölçümü}

In vitro XO inhibisyon analiz metodu, Sweeney ve arkadaşları tarafindan bildirilmiştir [25]. Enzim aktivitesi, ürik asit oluşumunun, $37{ }^{\circ} \mathrm{C}^{\prime} \mathrm{de}, 294$ nm'de Shimadzu UV-1601 spektrofotometre ile ölçülmesiyle test edildi. XO inhibisyonunun $\mathrm{IC}_{50}$ değerinin hesaplanması için reaksiyon karıșımına farklı konsantrasyonlarda allopurinol, 4 ve 5 bileşikleri eklendi. Kısaca, enzim tahlil protokolü; fosfat tamponu $(50 \mathrm{mM}, \mathrm{pH}=7.4), \mathrm{XO}(0.2 \mathrm{U})$ ve ksantin $(1 \mathrm{mM})$ içerir. Enzim, test edilen bileşiklerle (10 dakika) önceden inkübe edildi, daha sonra reaksiyon karışımına ksantin ilave edilerek reaksiyon başlatıldı. Test edilen bileşikler DMSO içinde çözüldü, sonra fosfat tamponu ile seyreltildi, reaksiyon karışımındaki son DMSO konsantrasyonu, $(\% 0.01 \mathrm{~h} / \mathrm{h})$ 'den daha düşüktü ve bu oran, enzim tahlili ile etkileşime girmez [26]. Tüm deneyler üç tekrar halinde gerçekleştirildi ve değerler üç deney sonucu olarak ifade edildi. Allopurinol pozitif kontrol olarak kullanıldı. Tüm bileşiklerin $\mathrm{IC}_{50}$ değerleri, XO inhibisyonunun, inhibitör yokluğunda ürün oluşumuna kıyasla, ürik asit oluşumundaki azalma açısından incelenerek ölçüldü. $\mathrm{XO}$ aktivitesinin $\mathrm{IC}_{50}$ inhibisyon yüzdesi aşağıdaki şekilde hesaplandı:

İnhibisyon $(\%)=(\mathrm{A}-\mathrm{B}) / \mathrm{A} \times 100$

A = Test bileşiği olmadan 294 nm'de alınan absorbans değeri,

$\mathrm{B}=$ Test bileşiği ile 294 nm'de alınan absorbans değeri. 


\subsection{Moleküler doking Çalışması}

Moleküler doking analizleri, hedef protein ile bir inhibitör molekül arasındaki etkileşimi keşfetmek için kullanılan en uygun yaklaşımdır [27-30]. Doking çalışmaları UCSF Chimera (1.13.1) programı ile gerçekleştirildi. Protein 3D kristalografik yapısı Protein Data Bank'tan (www.rcsb.org), (PDB ID:3NVY) indirildi [31]. Bileşiklerin (4, 5 ve allopurinol) 2D yapıları ChemDraw Ultra 12.0 ile çizildi. Avogadro software [32] ile 2D çizimleri optimize edildi. Bağlanma için proteinin su ve diğer kalıntıları UCSF Chimera (1.13.1) ile silindi [33]. UCSF Chimera (1.13.1) araçlarından Dock Prep ile polar hidrojenler ve Gasteiger yükleri eklendi. Autodock Vina [34] ile Grid kutusu hazırlandı. Grid kutusu

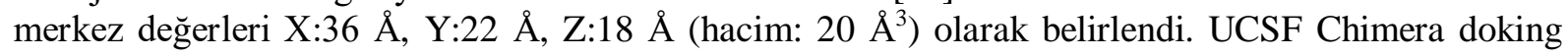
sonuçları, Discovery Studio Visualizer [35] ile görüntülendi.

\section{Sonuç}

Uzun yıllardır XO enzim inhibisyonu için kullanılan etkin ilaç allopurinoldür. Ancak, allopurinolün yapısal olarak pürin ihtiva etmesi ve ciddi yan etkilerinin [5] olması bu ilacın kullanımını kısıtlamaktadır. $\mathrm{Bu}$ nedenle allopurinole alternatif, pürin içermeyen yeni ilaçların keşfine ihtiyaç duyulmaktadır. Yapılan bu çalışma ile allopurinolden daha aktif ve pürin içermeyen yeni 1,2,3-triazol (4 ve 5) bileşikleri sententezlendi. Yapılan moleküler doking çalışmaları ile ksantin oksidaz enziminin aktif kısmı ile 4, 5 ve allopurinol bileşiklerinin bağlanma modları belirlendi. Bu etkileşimlere göre; $\mathbf{4}$ ve 5 bileşikleri yapısal olarak incelendiğinde aromatik grupların bağlanmada daha etkili olduğu görüldü.

\section{Teşekkür}

Çalışmalarımda desteğini esirgemeyen Sayın Samir Abbas Ali Noma'ya, değerli hocalarım Prof. Dr. Burhan ATEŞ ve Prof. Dr. Yunus KARA'ya, aynı zamanda Atatürk Üniversitesi'ne teşekkür ederim.

\section{Yazarların Katkısı}

Bu makale tek isimli bir çalışma olup, tüm katkı yazara aittir.

\section{Çıkar Çatışması Beyanı}

Yazarlar arasında herhangi bir çıkar çatışması bulunmamaktadır

\section{Araştırma ve Yayın Etiği Beyanı}

Yapılan çalışmada, araştırma ve yayın etiğine uyulmuştur. Araştırma etik kurul izni gerektirmemektedir.

\section{Kaynaklar}

[1] Mehta S.K., Nayeem N. 2014. Natural xanthine oxidase inhibitors for management of gout: a review. Research and reviews: journal of medical and health sciences, 3: 4-13.

[2] Borges F., Fernandes E., Roleira F. 2002. Progress towards the discovery of xanthine oxidase inhibitors. Current medicinal chemistry, 9: 195-217.

[3] Kıbrız İ.E., Saçmacı M., Yıldırım İ., Abbas Ali Noma S., Taşkın T.T., Ateş B. 2018. Xanthine oxidase inhibitory activity of new pyrrole carboxamide derivatives: In vitro and in silico studies. Archiv der pharmazie, 351 (10): 1800165.

[4] Pacher P., Nivorozhkin A., Szabo C. 2006. Therapeutic effects of xanthine oxidase inhibitors: renaissance half a century after the discovery of allopurinol. Pharmacological reviews, 58: 87114.

[5] Baldwin J., Kasinger P., Novello F., Sprague J., Duggan D. 1975. 4-trifluoromethylimidazoles and 5-(4-pyridyl)-1, 2, 4-triazoles, new classes of xanthine oxidase inhibitors. Journal of medicinal chemistry, 18: 895-900. 
[6] Wang S., Yan J., Wang J., Chen J., Zhang T., Zhao Y., Xue M. 2010. Synthesis of some 5phenylisoxazole-3-carboxylic acid derivatives as potent xanthine oxidase inhibitors. European journal of medicinal chemistry, 45: 2663-2670.

[7] Ishibuchi S., Morimoto H., Oe T., Ikebe T., Inoue H., Fukunari A., Kamezawa M., Yamada I., Naka Y. 2001. Synthesis and structure-activity relationships of 1-phenylpyrazoles as xanthine oxidase inhibitors. Bioorganic \& medicinal chemistry letters, 11: 879-882.

[8] Shukla S., Kumar D., Ojha R., Gupta M.K., Nepali K., Bedi P.M. 2014. 4, 6diaryl/heteroarylpyrimidin-2 (1h)-ones as a new class of xanthine oxidase inhibitors. Archiv der pharmazie, 347: 486-495.

[9] Song J.U., Choi S.P., Kim T.H., Jung C.-K., Lee J.-Y., Jung S.-H., Kim G.T. 2015. Design and synthesis of novel 2-(indol-5-yl) thiazole derivatives as xanthine oxidase inhibitors. Bioorganic \& medicinal chemistry letters, 25: 1254-1258.

[10] Phatak P.S., Bakale R.D., Dhumal S.T., Dahiwade L.K., Choudhari P.B., Krishna V.S., Sriram D., Haval K.P. 2019. Synthesis, antitubercular evaluation and molecular docking studies of phthalimide bearing 1,2,3-triazoles. Synthetic communications, 49: 2017-2028.

[11] Rajasekar S., Anbarasan P. 2019. A general proline catalyzed synthesis of 4, 5-disubstituted nsulfonyl-1, 2, 3-triazoles from 1, 3-dicarbonyl compounds and sulfonyl azide. Chemistry-an asian journal, https://doi.org/10.1002/asia.201901015.

[12] Kushwaha K., Kaushik N., Jain S.C. 2014. Design and synthesis of novel 2H-chromen-2-one derivatives bearing 1, 2, 3-triazole moiety as lead antimicrobials. Bioorganic \& medicinal chemistry letters, 24: 1795-1801.

[13] Wang G., Peng Z., Wang J., Li J., Li X.2016. Synthesis and biological evaluation of novel 2, 4, 5-triarylimidazole-1, 2, 3-triazole derivatives via click chemistry as $\alpha$-glucosidase inhibitors. Bioorganic \& medicinal chemistry letters, 26: 5719-5723.

[14] Li L.-T., Zhou L.-F., Li Y.-J., Huang J., Liu R.-H., Wang B., Wang P. 2012. Facile synthesis of 1, 2, 3-triazole analogs of SGLT2 inhibitors by 'click chemistry. Bioorganic \& medicinal chemistry letters, 22: 642-644.

[15] Röhrig U.F., Majjigapu S.R., Grosdidier A.I., Bron S., Stroobant V., Pilotte L., Colau D., Vogel P., Van den Eynde B.J., Zoete V. 2012. Rational design of 4-aryl-1, 2, 3-triazoles for indoleamine 2, 3-dioxygenase 1 inhibition. Journal of medicinal chemistry, 55: 5270-5290.

[16] González-Olvera R., Espinoza-Vázquez A., Negrón-Silva G., Palomar-Pardavé M., RomeroRomo M., Santillan R. 2013. Multicomponent click synthesis of new 1, 2, 3-triazole derivatives of pyrimidine nucleobases: Promising acidic corrosion inhibitors for steel. Molecules, 18: 1506415079.

[17] DiFrancesco D., Pinhas A.R. 1986. The nickel-promoted 1, 3-migration of an sp2 center; ring expansion of a vinylcyclobutene. The Journal of organic chemistry, 51: 2098-2102.

[18] Kuhn T., Tamm C., Riesen A., Zehnder M. 1989. Stereoselective hydrolysis of the dimethyl 4, 5epoxy-1, 2-cis-cyclohexanedicarboxylates with pig liver esterase (PLE). Tetrahedron letters, 30: 693-696.

[19] Hudlicky T., Fan R., Reed J.W., Gadamasetti K.G. 1992. Divinylcyclopropane-cycloheptadiene rearrangement. Org. React., (Hoboken, NJ, U. S.) 41: No pp. given.

[20] Voskresenskii V.A., Shakirzyanova S.S., Byl'ev V.A. 1962. Some regularities in the plasticizing of poly(vinyl chloride) with oxides of tetrahydrophthalates. Izv. vyssh. uchebn. zaved., khim. khim. tekhnol., 5: 322-325.

[21] Acquaah-Harrison, G. 2010. Antibacterial agents: 1, 4-disubstituted 1, 2, 3-triazole analogs of the oxazolidinone. Doctor of philosophy, The faculty of the college of arts and sciences of Ohio University.

[22] Himo F., Lovell T., Hilgraf R., Rostovtsev V.V., Noodleman L., Sharpless K.B., Fokin V.V. 2005. Copper (I)-catalyzed synthesis of azoles. DFT study predicts unprecedented reactivity and intermediates. Journal of the american chemical society, 127: 210-216.

[23] Worrell B.T., Malik J.A., Fokin V.V. 2013. Direct evidence of a dinuclear copper intermediate in $\mathrm{Cu}$ (I)-catalyzed azide-alkyne cycloadditions. Science, 340: 457-460.

[24] Tan A. 2020. Novel 1, 2, 3-triazole compounds: Synthesis, In vitro xanthine oxidase inhibitory activity, and molecular docking studies. J. Mol. Struct., 128060. 
[25] Sweeney A.P., Wyllie S.G., Shalliker R.A., Markham J. 2001. Xanthine oxidase inhibitory activity of selected Australian native plants. Journal of ethnopharmacology, 75 (2-3): 273-277.

[26] Nile S.H., Kumar B., Park S.W. 2013. In vitro evaluation of selected benzimidazole derivatives as an antioxidant and xanthine oxidase inhibitors. Chemical biology \& drug design., 82: 290-295.

[27] Hassan M., Ashraf Z., Abbas Q., Raza H., Seo S.-Y. 2018. Exploration of novel human tyrosinase inhibitors by molecular modeling, docking and simulation studies. Interdisciplinary sciences: computational life sciences, 10: 68-80.

[28] Hassan M., Abbas Q., Ashraf Z.A. Moustafa A., Seo S.-Y. 2017. Pharmacoinformatics exploration of polyphenol oxidases leading to novel inhibitors by virtual screening and molecular dynamic simulation study. Computational biology and chemistry, 68: 131-142.

[29] Langham J. 2014. Ranking small molecules by how much they preferentially inhibit the growth of cancer cell lines with either BRAF or KRAS oncogene mutations. Peer J PrePrints, 2: e532v1.

[30] Maroli N., Kolandaivel P., 2019. Comparative study of stability and transport of molecules through cyclic peptide nanotube and aquaporin: A molecular dynamics simulation approach. Journal of Biomolecular Structure and Dynamics, 1-14.

[31] Berman H., Westbrook J., Feng Z., Gilliland G., Bhat T., Weissig H., Shindyalov I., Bourne P. 2000. The protein data Bank nucleic acids research, 28: 235-242. URL: www. rcsb. org Citation.

[32] Hanwell M.D., Curtis D.E., Lonie D.C., Vandermeersch T., Zurek E., Hutchison G.R. 2012. Avogadro: an advanced semantic chemical editor, visualization, and analysis platform. Journal of cheminformatics, 4 (1): 17.

[33] Pettersen E.F., Goddard T.D., Huang C.C., Couch G.S., Greenblatt D.M., Meng E.C., Ferrin T. E. 2004. UCSF Chimera-a visualization system for exploratory research and analysis. Journal of computational chemistry, 25 (13): 1605-1612.

[34] Trott O., Olson A.J. 2010. AutoDock Vina: improving the speed and accuracy of docking with a new scoring function, efficient optimization, and multithreading. Journal of computational chemistry, 31: 455-461.

[35] Biovia D.S. 2017. Discovery studio visualizer, Release 2017, San Diego: Dassault Systèmes, 2016. to be found under http://accelrys. com/products/collaborative-science/biovia-discoverystudio/visualization-download. php (accessed: 12.12.2017). 